\title{
Kernos
}

Revue internationale et pluridisciplinaire de religion grecque antique

$10 \mid 1997$

Varia

\section{Fr. DÍEZ DE VELASCO, Los caminos de la muerte}

\section{Isabelle Tassignon}

\section{(2) OpenEdition}

\section{Journals}

Édition électronique

URL : http://journals.openedition.org/kernos/674

DOI : $10.4000 /$ kernos. 674

ISSN : 2034-7871

Éditeur

Centre international d'étude de la religion grecque antique

Édition imprimée

Date de publication : 1 janvier 1997

Pagination : 335-336

ISSN : 0776-3824

Référence électronique

Isabelle Tassignon, «Fr. díEZ dE VELASco, Los caminos de la muerte», Kernos [En ligne], 10 | 1997, mis en ligne le 12 avril 2011, consulté le 24 septembre 2020. URL : http://journals.openedition.org/kernos/ 674 ; DOI : https://doi.org/10.4000/kernos.674 
analyses, le plus souvent convaincantes, rend ainsi intelligibles des scènes difficiles où la présence de telle figure restait incompréhensible ou dont le sens général échappait. Sans doute, le parti choisi de diviser ces figures en trois groupes, d'ailleurs très inégaux en nombre comme en intérêt, conduit-il à quelques redites et donne-t-il parfois l'impression, vite dissipée, de tourner en rond. Mais surtout, l'A. prend soin de situer les Personnifications italiotes entre celles de la Grèce et celles de Rome. Il a bien notion de ce que cet art, pour neuf et original qu'il soit, doit à la littérature et aux arts figurés grecs. À maintes reprises, il fait appel au théâtre, dans sa forme écrite ou visuelle, à la poésie, à la céramique peinte de la Grèce. Néanmoins, lorsque l'analyse des Érinyes comme représentantes de la justice cosmique chez Homère apparaît à la p. 72 ou encore celle qui concerne l'organisation des puissances hésiodiques à la p. 187 dans la conclusion, on se prend à souhaiter - mais était-ce possible ? - une dimension historique et évolutive plus systématique de la réflexion sur le problème des Personnifications.

Marie-Christine VILLANUEVA PUIG (Centre Louis Gernet, CNRS, Paris)

\section{Francesco DIEz de Velasco, Los caminos de la muerte. Religión, rito e imágenes del paso al más allá en la Grecia antigua, Madrid, Ed. Trotta, 1995. 1 vol. $14,5 \times 23 \mathrm{~cm}, 198$ p. (Coll. Paradigmas). ISBN : 84-8164-016-6.}

Les lécythes à fond blanc et les textes des lamelles orphiques fournissent à l'A. une abondante documentation lui permettant de rendre compte de la multiplicité des perceptions de la mort et de l'image du chemin vers l'Au-delà. Après une introduction consacrée aux méthodes tirées de la sociologie et de l'iconographie, c'est à Ulysse « revenant», Ulysse que tous tenaient pour mort, que l'A. consacre un premier chapitre. Les deux chapitres qui suivent analysent tout d'abord les représentations iconographiques des personnages psychopompes et par là, la conception du guide sur les chemins de l'Au-delà; ce sont ensuite les différents types de représentations du mort, sous forme de corps entier, immobile, ou sous forme d'eidôlon, image désincarnée du défunt que l'A. étudie. Un long développement lui est consacré; l'A. y passe en revue les différents contextes iconographiques où apparaît l'eidôlon.

Les images des lécythes sont claires : le chemin vers l'Au-delà est certes un chemin sans retour mais les défunts morts de «belle mort » s'abandonnent sans crainte à leur guide, qu'il soit Hermès, Charon ou le couple Hypnos-Thanatos. Cette conception sereine du chemin vers l'Au-delà est née dans l'Athènes démocratique du ve siècle. Parallèlement à cela, existe une conception plus angoissante du chemin outre-tombe; celle-ci est héritée de traditions indo-européennes, mais reste marginale. C'est celle d'une mort ravisseuse, semeuse d'épouvante qu'incarnent les Harpies, les sirènes et la Gorgone. Le quatrième chapitre est une comparaison entre le tantrisme indien et les ascèses mystiques conduisant certains philosophes à tenter l'expérience de la mort; pour l'A., plusieurs récits de vie de devins grecs sont marqués par des éléments venus du tantrisme, comme la présence du serpent. Le dernier chapitre est consacré aux lamelles orphiques. C'est une conception de la mort qui est réservée au cercle restreint des initiés. Les conditions à remplir pour accomplir le voyage vers la divinité ne sont plus d'ordre social, mais se situent sur un plan spirituel: la pureté est la condition préalable pour commencer le chemin qui permet de se détacher des contingences terrestres pour d'accéder à la «vraie » vie. La mort n'est plus alors qu'un passage au terme 
duquel l'initié va rejoindre la divinité, Perséphone ou Dionysos. L'A., par son approche résolument originale des sources, renouvelle la perception de l'imaginaire funéraire aux époques archaïque et classique. Cette étude, à la fois iconographique et sociologique, constitue une riche contrepartie à des recherches archéologiques telles que celles entreprises par $\mathrm{J}$. de la Genière sur les nécropoles d'Italie du Sud ${ }^{33}$. L'ouvrage est accompagné d'illustrations bien choisies. Bibliographie et index des sources iconographiques en fin de volume.

Isabelle TASSIGNON (Université de Liège)

Odile WATTEL-DE CROIzANT, Les mosä̈ques représentant le mytbe d'Europe ( ${ }^{\text {er }}-V I^{e}$ siècles). Évolution et interprétation des modèles grecs en milieu romain, Paris, de Boccard, 1995. 1 vol. $16 \times 24 \mathrm{~cm}, 313$ p., 25 fig., 31 pl. (De l'archéologie à l'bistoire). ISBN : 2-7118-0091-9.

Madame Odile Wattel-de Croizant s'est proposé d'étudier dans cet ouvrage issu d'un doctorat d'État présenté à Tours en 1993 un ensemble de quarante-quatre mosaïques illustrant l'enlèvement d'Europe. Elle décrit la plupart des mosaïques, avec le vocabulaire technique propre à cet art, et les remet, aussi souvent qu'il est possible, dans leur contexte archéologique; enfin, elle joint, à la fin du volume, les reproductions en couleurs de nombre d'entre elles.

Le lecteur qui est initié à la science musivale (relative aux mosaïques) et qui possède des connaissances générales en archéologie sera sans conteste intéressé par cet impressionnant travail d'historienne de l'art, et ce n'est pas sur ce terrain que je porterai mes critiques. Je livrerai simplement quelques réflexions que la lecture de cet ouvrage peut susciter chez un philologue soucieux de comprendre les textes que l'A. invoque.

Dans un tel ouvrage, de toute évidence, il est impossible de se limiter à une description purement objective et matérielle: on en vient naturellement à une forme ou l'autre d'interprétation, sur la base de textes antiques cités en parallèle. Et c'est ici que les problèmes se posent. Il existe indubitablement, dans les représentations sur mosaïque, des couples formés d'un taureau à queue de Triton chevauché par une figure féminine. Cette femme est-elle une Europe ? Oui, dit Mme Wattel, en se référant à un passage des Dionysiaques de Nonnos le Panopolitain (I, 72-110). Que découvre celui qui se rapporte au texte grec? Que le taureau dont parle Nonnos n'est nullement un taureau marin par sa nature, mais qu'il est tout simplement comparé à un dauphin. C'est ainsi que la «queue de poisson » dont parle à plusieurs reprises Mme Wattel ne peut en aucune manière être celle du taureau qui porte Europe, mais celle d'un dauphin. Donc le texte de Nonnos ne peut servir à interpréter comme une Europe un personnage féminin chevauchant un animal hybride. Ceci disqualifie un certain nombre de représentations où l'A. interprète comme une Europe une femme à cheval sur le dos d'un taureau à queue de poisson.

Mme Wattel semble considérer qu'Europe est une « déesse au taureau », expression qu'elle emploie à de très nombreuses reprises. Mais elle n'avance aucune preuve,

33 J. DE LA GENIÈRE, Les sociêtés antiques à travers leurs nécropoles, in MEFRA, 102 (1990), p. 8491. 